\title{
Evaluation of the Impact of Self-efficacy-based Training on Depression, Self-Care Behaviors, and Quality of Life in Patients with Irritable Bowel Syndrome
}

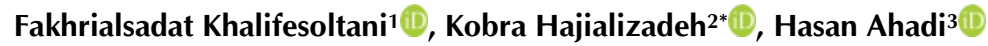 \\ 1 Department of Psychology, Kish International Branch, Islamic Azad University, Kish Island, Iran \\ 2 Associate Professor, Department of Psychology, Bandar Abbas Branch, Islamic Azad University, Bandar \\ Abbas, Iran \\ 3 Professor, Department of Psychology, Karaj Branch, Islamic Azad University, Karaj, Iran
}

*Corresponding author:

Kobra Hajializadeh, Department of

Psychology, Bandar Abbas Branch,

Islamic Azad University, Bandar

Abbas, Iran

Tel: 0313133375332

Email:Ph_alizadeh@yahoo.com

Received: 23 Jun. 2020

Accepted: 08 Sep. 2020

ePublished: 01 May. 2021

\begin{abstract}
Background and Objective: Irritable bowel syndrome is the most common diagnosis among patients with gastrointestinal diseases and can adversely affect their quality of life. In this regard, the present study aimed to evaluate the effectiveness of self-efficacy-based training on depression, self-care behaviors, and the quality of life of patients with irritable bowel syndrome.

Materials and Methods: This applied quasi-intervention study was conducted based on a pretestposttest design with a control group and follow-up. The statistical population included all patients with irritable bowel syndrome who referred to Khorshid Hospital in Isfahan, Iran from September to November 2019. The samples were selected using the convenience sampling method. In total, 30 patients with irritable bowel syndrome were included in the study and randomly divided into two groups of intervention and control. The data were collected using Beck depression inventory, selfcare questionnaire, and quality of life questionnaire. The intervention group received four sessions of self-efficacy training (one session per week for $90 \mathrm{~min}$ ), while the control group did not receive any training. Two months later, the follow-up period was completed. The collected data were analyzed using repeated measures of analysis of variance in SPSS software (version 22).

Results: The results showed that self-efficacy training was effective in decreasing depression $(\mathrm{P}<0.0001, \mathrm{~F}=35.39)$ and increasing quality of life $(\mathrm{P}<0.0001, \mathrm{~F}=120.30)$ and self-care behaviors $(\mathrm{P}<0.0001, \mathrm{~F}=70.50)$ in patients with irritable bowel syndrome.

Conclusions: It can be concluded that training based on self-efficacy theory can effectively reduce depression and increase self-care behaviors and quality of life in patients with irritable bowel syndrome.
\end{abstract}

Keywords: Depression, Irritable bowel syndrome, Quality of life, Self-care, Self-efficacy

\section{Background}

Irritable bowel syndrome is the most common diagnosis among patients with gastrointestinal diseases and accounts for $25-50 \%$ of cases referred to gastroenterologists [1]. Anxiety and depression are common among these patients and are strongly associated with the onset and severity of symptoms. Irritable bowel syndrome is a problem that mainly affects the large intestine [2].

Nowadays, evaluation of the quality of life is an essential part of medical evaluation and health status assessment of patients with irritable bowel syndrome [3] since the quality of life is an important concept among these patients. It is considered a multidimensional concept, including physical, psycho-social, and recovery functions. Chronic complications of irritable bowel syndrome, reduced life expectancy, and mortality caused by it impose much economic burden on the patients and their families [4].

One of the major goals of controlling irritable bowel syndrome is to empower patients to selfcare [5]. Irritable bowel syndrome is a chronic disease that requires lifelong self-care behaviors. Effective management of this syndrome needs complex self-care behaviors, such as lifestyle changes, nutrition intake control, regular exercise, medications, control and measurement of the glucose level, and foot care [6-8].

According to the results of the previous research performed on the relationship between psychosocial factors and irritable bowel syndrome, subjects with irritable bowel syndrome had higher levels of depression, anxiety, and neuroticism, compared to healthy people [9]. Results of a study conducted by Pinto et al. [10] also indicated that $50 \%$ of people with irritable bowel syndrome suffer from anxiety 
and depression.

In addition, some patients with this syndrome who referred to subspecialty centers suffer from anxiety, depression, phobia, and somatization. These patients rarely have complete symptoms of mental disease. Moreover, those patients with irritable bowel syndrome who have not referred to a hospital cannot be distinguished from healthy people in terms of mental health problems [11]. Patients with irritable bowel syndrome are likely to have been physically or sexually abused in the past or have a learned behavioral pattern from childhood. Based on the findings of a study, these patients showed more neurosis compared to healthy people [12].

Learning principles as well as human behavior theories and models provide a framework for understanding how people learn and behave; moreover, they are the basis of effective behavior change interventions [13]. Health education professionals must apply a variety of theories to complete educational strategies. They are recommended to apply the most relevant theories based on the spatial and temporal conditions of the patients [14,15]. Cong et al. [16] performed a study titled "The effect of self-efficacy interventions in people with irritable bowel syndrome: A systematic review study". They found strong evidence regarding the impact of self-efficacy interventions on the improvement of short-term symptoms and quality of life; however, the long-term results were different.

Results of a study conducted by Shahabi et al. [17] showed that self-efficacy therapy led to improvement after the treatment. The number of patients with irritable bowel syndrome is growing and they have major problems with depression and self-care behaviors. However, it seems that many of these patients do not have enough knowledge and skills to properly manage such problems.

\section{Objectives}

The present study aimed to evaluate the effect of training based on self-efficacy theory on depression, self-care behaviors, and the quality of life of patients with irritable bowel syndrome.

\section{Materials and Methods}

The present applied quasi-intervention study was conducted based on a pretest-posttest design with a control group and follow-up. The statistical population of this study included all patients with irritable bowel syndrome who referred to Khorshid Hospital in Isfahan, Iran between September and November 2019. First, 30 out of 61 patients with irritable bowel syndrome were selected based on inclusion and exclusion criteria. Afterward, they were randomly allocated to intervention and control groups. The training sessions were held at Khorshid Hospital.

The samples were selected using the purposeful sampling method. The sample size was calculated at 30 people by using $G^{*}$ Power software (version 1.3.9.2) (without the need for formula and by specification of the statistical tests, test power, $\alpha=0.05$ error, and $\beta=0.80$ error). The inclusion criteria were 1) diagnosis of irritable bowel syndrome based on the criteria of Rome II [18] by a gastroenterologist, 2) lack of receiving psychological treatment during the last three months, 3) no severe psychiatric diseases among first-degree family members, and 4) a family history of colon cancer. Exclusion criteria were symptoms, such as gastrointestinal bleeding, blood in the stool, absence from more than two sessions of training sessions, and hospitalization during the study period.

Ethical considerations of the present study were as follows: 1) all individuals received written information about the research and participation was voluntary, 2) the subjects were ensured that all of their information would remain confidential and be used only for research purposes, 3) the first and last names of the participants were not registered to keep their information confidential, and 4) all questionnaires were completed with the help of the researcher to ensure that they are filled correctly. The researcher also provided the intervention for the control group at the end of the study to comply with ethical principles.

This research was conducted after obtaining the permission from Research Deputy of Hormozgan University of Medical Sciences (code of ethics: IR.HUMS.REC.1398.311). Moreover, it was confirmed by the Clinical Trials Registration Center, Iran (code: IRCT20191217045761N1).

\section{Beck Depression Inventory}

The second edition of the Beck Depression Inventory [18] was developed to assess the severity of depression and complies with DSM-IV depression criteria. The questionnaire consists of 21 items that are scored based on a four-point Likert scale ranging from 0 to 3 . It should be mentioned that the total score ranges from 0 to 63 , and high scores indicate more severe depression. The cutoff point in the Beck Depression Inventory is 13.

Test-retest reliability with a one-week interval was obtained at 0.93 and its internal consistency was obtained at 0.91 by Cronbach's alpha [18]. Cronbach's alpha method was used to investigate the internal consistency and the alpha coefficient of 
Table 1. Description of self-efficacy training sessions

\begin{tabular}{lc}
\hline Sessions & Description of sessions \\
\hline Session 1 & $\begin{array}{r}\text { Information was given to raise awareness, and training packages were provided for learners. The learners were asked to } \\
\text { share their successful experiences regarding health-promoting behaviors for other participants (success in performance). } \\
\text { Observational learning and modeling were strengthened, successful people in terms of health-promoting behaviors were } \\
\text { asked to share their experiences with others. For this purpose, for example, a person who was successful at stress } \\
\text { management was invited to share his/her experiences with others as a role model and answer questions of other health } \\
\text { volunteers participating in the class (experiences of success and role modeling). }\end{array}$ \\
Session 2 & $\begin{array}{r}\text { To motivate verbal encouragement in theoretical sessions, learners who participate in the discussion received } \\
\text { encouragement. Personal counseling was also provided to encourage learners who were not very successful in performing } \\
\text { health-promoting behaviors to perform these behaviors. The participants were asked to make their decisions in smaller and } \\
\text { more accessible steps. }\end{array}$ \\
& $\begin{array}{c}\text { To have physiological states that could help learners increase their sense of self-efficacy, people were allowed to express } \\
\text { their thoughts and feelings while doing physical activity following a healthy diet, and performing stress management } \\
\text { practices. }\end{array}$ \\
\hline
\end{tabular}

0.90 was obtained for the whole questionnaire [19]. Cronbach's alpha of this questionnaire was obtained at 0.74 in the present study.

\section{Self-care Questionnaire}

A 13-item questionnaire prepared by Alizadeh Aghdam et al. [20] was used to investigate the level of self-care. This questionnaire included various aspects, namely healthy nutrition ( 3 items), physical activity (2 items), stress management (3 items), tobacco consumption ( 2 items), and awareness and responsibility for health status (3 items). This questionnaire is scored based on a five-point Likert scale ranging from 1 to 5 . The lowest and highest scores of this questionnaire were 13 and 65, respectively. The score ranges of $13-29,31-47$, and 48-65 on this questionnaire indicate low, moderate, and high levels of self-care, respectively. This tool had good reliability and its Cronbach's alpha was obtained at 0.83 [21]. In the present study, Cronbach's alpha of this questionnaire was obtained at 0.83 .

\section{Quality of Life Questionnaire}

This self-report questionnaire, mainly used to assess the quality of life and health, was developed by Ware and Sherbourne [22] and consists of 36 items. It assesses eight domains of physical functions, social functions, physical role-play, emotional roleplay, mental health, vitality, physical pain, and general health. Scores of the subjects in each of these domains vary between 0 and 100, and higher scores indicate higher quality of life. Validity and reliability of this questionnaire were confirmed in Iran and the coefficients of internal consistency of its eight subscales were reported between 0.70 and 0.85 . Moreover, the test-retest coefficients of the subscales with one-week interval were reported at 0.43-0.79 [22].

Cronbach's alpha of this questionnaire was obtained at 0.77 in the present study. The training intervention was implemented based on the protocol of the self-efficacy theory of Stajkovic, Bandura, Locke, Lee, and Sergent [23] in five 60min training sessions. These sessions included lecture, question and answer, group discussion, and individual counseling methods (Table 1).

In the descriptive statistics section, frequency tables and charts as well as central and distribution indices, such as mean and standard deviation values, were calculated. In the inferential statistics section, the MANCOVA method and repeated measures of variance analysis were used. The above-mentioned statistical analyses were performed in SPSS software (version 22).

\section{Results}

The findings were analyzed using descriptive statistics, including mean, standard deviation, number of subjects, frequency table, and percentage. The results of the analysis are summarized for all variables of the study in the following tables (tables 1 and 2).

Since the results of Box's M test were not significant

Table 2. Frequency distribution and comparison of demographic characteristics of research subjects

\begin{tabular}{llccc}
\hline Demographic variables & Intervention & Control & p-value \\
\hline \multirow{2}{*}{ Gender } & Female & $6(40)$ & $4(26.7)$ & 0.33 \\
& Male & $9(60)$ & $11(73.3)$ & 1.00 \\
\multirow{4}{*}{ Marital status } & Single & $0(0.0)$ & $1(6.7)$ & \\
& Married & $15(100)$ & $14(93.3)$ & 0.43 \\
& Under 30 years old & $1(6.7)$ & $0(0.0)$ & \\
\multirow{2}{*}{ Education level } & $30-39$ years & $10(66.7)$ & $10(66.7)$ & $5(33.3)$ \\
& $40-49$ years & $4(26.7)$ & $0(0.0)$ & \\
& Illiterate & $1(6.7)$ & $14(93.3)$ & 0.08 \\
& Diploma & $11(73.3)$ & $0(0.0)$ & \\
& Associate's degree & $2(13.3)$ & $1(6.7)$ & \\
\hline
\end{tabular}


Table 3. Mean and standard deviation of research variables in the intervention and control groups

\begin{tabular}{|c|c|c|c|c|c|c|c|}
\hline \multirow{2}{*}{ Variable } & \multirow{2}{*}{ Group } & \multicolumn{2}{|c|}{ Pre-test } & \multicolumn{2}{|c|}{ Post-test } & \multicolumn{2}{|c|}{ Follow-up } \\
\hline & & Mean & SD & Mean & SD & Mean & SD \\
\hline \multirow{2}{*}{ Depression } & Intervention & 13.66 & 1.29 & 11.60 & 1.18 & 12.06 & 1.38 \\
\hline & Control & 12.73 & 1.27 & 12.20 & 1.26 & 12.80 & 1.20 \\
\hline \multirow{2}{*}{ Quality of life } & Intervention & 159.86 & 4.74 & 165.53 & 4.12 & 164.80 & 4.02 \\
\hline & Control & 160 & 4.59 & 160.53 & 4.70 & 160.46 & 4.77 \\
\hline \multirow{2}{*}{ Self-care } & Intervention & 28.06 & 4.43 & 31.80 & 4.31 & 31.13 & 4.42 \\
\hline & Control & 30.60 & 4.13 & 31.26 & 4.00 & 31.46 & 3.96 \\
\hline
\end{tabular}

for any of the research variables, the homogeneity of the variance-covariance matrices was confirmed. Moreover, the lack of significance of any of the variables in Levene's test showed that the intergroup variances and the level of variance of the dependent variable error in all groups were equal. Finally, the examination of the results of Mauchly's test of sphericity indicated that this test was significant for the variable of quality of life; hence, assumption of the equality of intra-subject variances (sphericity assumption) has not been observed (Mauchly's W=0.39; d=2=0.001; $\mathrm{P}=0.31$ ). The Lambda Wilkes test with a value of 0.12 and the $\mathrm{F}=95.32$ showed a significant difference between the effectiveness scores of self-efficacy theory training on the improvement of depression, quality of life, and self-care in the intervention and control groups with a significance level of 0.0001 .

According to Table 4, the score of depression in the post-test stage in the intervention group is less than that of the pre-test stage in the control group (lower scores in the post-test stage indicate lower levels of depression). In other words, the selfefficacy intervention was highly effective in the improvement of depression. The results also indicated that depression in the follow-up stage in the self-efficacy theory training group decreased significantly, compared to the post-test stage in the control group. In addition, the score of quality of life at the post-test stage was higher in the intervention group, compared to the control group.

Table 4. Results of Bonferroni post-hoc test for comparison of research variables

\begin{tabular}{|c|c|c|c|c|}
\hline Variable & Group & Stages & Post-test & Follow-up \\
\hline \multirow{4}{*}{ Depression } & \multirow{2}{*}{ Self-efficacy theory training } & Pre-test & $30.1^{*}$ & $0.76^{*}$ \\
\hline & & Post-test & - & $-0.53^{*}$ \\
\hline & \multirow{2}{*}{ Control group } & Pre-test & 0.09 & 0.12 \\
\hline & & Post-test & - & 0.05 \\
\hline \multirow{4}{*}{ Quality of life } & \multirow{2}{*}{ Self-efficacy theory training } & Pre-test & $-3.10^{*}$ & $-2.70 *$ \\
\hline & & Post-test & - & $0.40^{*}$ \\
\hline & \multirow{2}{*}{ Control group } & Pre-test & -0.03 & -0.07 \\
\hline & & Post-test & - & 0.05 \\
\hline \multirow{4}{*}{ Self-care behaviors } & \multirow{2}{*}{ Self-efficacy theory training } & Pre-test & $-2.20^{*}$ & $-1.96^{*}$ \\
\hline & & Post-test & - & 0.23 \\
\hline & \multirow{2}{*}{ Control group } & Pre-test & -0.06 & -0.08 \\
\hline & & Post-test & - & -0.11 \\
\hline
\end{tabular}

\section{Discussion}

Based on the obtained results, the self-efficacy theory training has been highly effective in the improvement of depression. The results also revealed that depression in the follow-up stage in the self-efficacy theory training group decreased significantly, compared to the control group. These results were in line with those of the research conducted by Cong et al. [16] and Shahabi et al. [17]. In explaining these results, it can be stated that selfefficacy is a factor that causes a kind of selfconfidence, self-esteem, and courage in a person. Therefore, it leads to more participation in social interactions and increases the level of social skills of people. Within the cognitive-social approach framework, Bandura considers self-efficacy as one's belief in their abilities in the performance of certain activities [24].

In this regard, according to Bandura, self-efficacy is one of the most important factors in the development of healthy social communication that makes life enjoyable and empowers people to cope with long-term pressures. Based on Bandura's theory, high self-efficacy helps to create a sense of relaxation in the face of difficult problems, and vice versa, people with low self-efficacy suffer stress, anxiety, and depression in difficult situations, which weakens their thinking and performance abilities [25-28].

Effectiveness of self-efficacy training on self-care behaviors could be explained by saying that such skills help people cope more effectively with stressful situations. Accordingly, in the face of problems, they try to reduce their stress and focus on their abilities and capabilities to create a happier and healthier life. Since this program targets maladjusted cognitive styles and information process biases that are related to the self-care of 
people with irritable bowel syndrome, it will improve their self-care [29].

Furthermore, self-efficacy increases the use of problem-oriented coping responses in patients with irritable bowel syndrome and leads to the positive review and re-assessment of emotion regulation [30]. Self-efficacy training provides a belief in one's abilities and an optimistic philosophy in life. It is one of the constructive elements of action that restores belief and gives people the courage to do the work and makes them aware of their values and strengths through encouragement [31].

Results of this study are limited to patients with irritable bowel syndrome since it was conducted only on the patients with irritable bowel syndrome in Isfahan and caution should be exercised in generalizing the results to other regions and cities. It is recommended that this type of study be conducted on another sample group and its results be evaluated and compared with those of this study. It is also suggested that this type of study be performed in other cities and its results be evaluated. Moreover, it is recommended for future studies to provide follow-up in the form of personal counseling after the group training.

\section{Conclusions}

It can be concluded that intervention based on selfefficacy theory is effective in reducing depression and increasing self-care behaviors and quality of life in patients with irritable bowel syndrome.

\section{Compliance with ethical guidelines}

All ethical principles were considered in this research.; accordingly, the participants were informed about the purpose of the research and its stages. Besides, written informed consent was obtained from the subjects, and they were also assured of the confidentiality of their information. Moreover, the subjects were free to withdraw from the study at any time. They were also informed that they would be provided with the results of the research.

\section{Acknowledgments}

The authors would like to thank the participants, who cooperated with them in this research project.

\section{Authors' contributions}

Conceptualization: Fakhrialsadat Khalifesoltani; Methodology: Kobra Hajializadeh; Investigation: Kobra Hajializadeh; Writing of the Original Draft: Fakhrialsadat Khalifesoltani; Writing of the Review and Editing: All Authors; Funding Acquisition: All Authors; References: All Authors; Supervision: Hasan Ahadi.

\section{Funding/Support}

This research did not receive any specific grant from funding agencies in the public, commercial, or not-for-profit sectors.

\section{Conflicts of Interest}

The authors declare that they have no conflict of interests.

\section{References}

1. Tap J, Derrien M, Turnblom H, Brazeilles R, Cools-Portier S, Dorn̆ J, et al. Identification of an intestinal microbiota signature associated with severity of irritable bowel syndrome. Gastroenterology. 2017; 152(1):111-23. [DOI: 10.1053/j.gastro. 2016.09.049] [PMID]

2. Rao SS, Yu S, Fedewa A. Systematic review: dietary fibre and FODMAP-restricted diet in the management of constipation and irritable bowel syndrome. Alimentary Pharmacology \& Therapeutics. 2015; 41(12):1256-70. [DOI:10.1111/apt.13167] [PMID]

3. Buono JL, Carson RT, Flores NM. Health-related quality of life, work productivity, and indirect costs among patients with irritable bowel syndrome with diarrhea. Health and Quality of Life Outcomes. 2017; 15(1):35-40. [DOI:10.1186/s12955-017-0611-2] [PMID] [PMCID]

4. Puvvada RC, Muthukumar VA. Impact of patient counselling on the knowledge, attitude, practice and quality of life in patients with hypertension with diabetes mellitus-II. hypertension. Indian Journal of Pharmaceutical Education and Research. 2018; 14(16):22-37.

5. Lee YJ, Shin SJ, Wang RH, Lin KD, Lee YL, Wang YH. Pathways of empowerment perceptions, health literacy, selfefficacy, and self-care behaviors to glycemic control in patients with type 2 diabetes mellitus. Patient Education and Counseling. 2016; 99(2):287-94. [DOI:10.1016/j.pec.2015. 08.021] [PMID]

6. Kauric-Klein Z, Peters RM, Yarandi HN. Self-efficacy and blood pressure self-care behaviors in patients on chronic hemodialysis. Western Journal of Nursing Research. 2017; 39(7):886-905. [DOI:10.1177/0193945916661322] [PMID]

7. Woda A, Belknap RA, Haglund K, Sebern M, Lawrence A. Factors influencing self-care behaviors of African Americans with heart failure: a photovoice project. Heart \& Lung. 2015; 44(1):33-8. [DOI:10.1016/j.hrtlng.2014.09.001] [PMID]

8. Ross S, Bossis A, Guss J, Agin-Liebes G, Malone T, Cohen B, et al. Rapid and sustained symptom reduction following psilocybin treatment for anxiety and depression in patients with life-threatening cancer: a randomized controlled trial Journal of Psychopharmacology. 2016; 30(12):1165-80. [DOI:10.1177/0269881116675512] [PMID] [PMCID]

9. Bai YM, Su TP, Li CT, Tsai SJ, Chen MH, Tu PC, et al. Comparison of pro-inflammatory cytokines among patients with bipolar disorder and unipolar depression and normal controls. Bipolar Disorders. 2015; 17(3):269-77. [DOI: 10.1111/bdi.12259] [PMID]

10. Paduano D, Cingolani A, Tanda E, Usai P. Effect of three diets (low-FODMAP, gluten-free and balanced) on irritable bowel syndrome symptoms and health-related quality of life. Nutrients. 2019; 11(7):1566-80. [DOI:10.3390/ nu11071566] [PMID] [PMCID]

11. Fischer A, Schruder J, Vettorazzi E, Wolf OT, Puttgen J, Lau $\mathrm{S}$, et al. An online programme to reduce depression in patients with multiple sclerosis: a randomised controlled trial. The Lancet Psychiatry. 2015; 2(3):217-23. [DOI: 10.1016/S2215-0366(14)00049-2] [PMID]

12. Murri MB, Respino $M$, Innamorati $M$, Cervetti $A$, Calcagno $P$, Pompili $M$, et al. Is good insight associated with depression among patients with schizophrenia? Systematic review and meta-analysis. Schizophrenia Research. 2015; 162(1-3):23447. [DOI:10.1016/j.schres.2015.01.003] [PMID]

13. Damush TM, Kroenke K, Bair MJ, Wu J, Tu W, Krebs EE, et al. Pain self-management training increases self-efficacy, self-management behaviours and pain and depression outcomes. European Journal of Pain. 2016; 20(7):1070-8. [DOI:10.1002/ejp.830] [PMID]

14. Lai C, Shum M, Tian Y. Enhancing learners' self-directed use of technology for language learning: the effectiveness of an online training platform. Computer Assisted Language Learning. 2016; 29(1):40-60. [DOI:10.1080/09588221.2014.889714]

15. Woelber JP, Spann-Aloge N, Hanna G, Fabry G, Frick K, Brueck $R$, et al. Training of dental professionals in motivational interviewing can heighten interdental cleaning self-efficacy in periodontal patients. Frontiers in Psychology. 2016; 7(2):254-63. [DOI:10.3389/fpsyg.2016.00254] [PMID] [PMCID]

16. Cong X, Perry M, Bernier KM, Young EE, Starkweather A. Effects of self-management interventions in patients with irritable bowel syndrome: systematic review. Western Journal of Nursing Research. 2018; 40(11):1698-720. [DOI:10.1177/0193945917727705] [PMID] [PMCID]

17. Shahabi L, Naliboff BD, Shapiro D. Self-regulation evaluation of therapeutic yoga and walking for patients with 
irritable bowel syndrome: a pilot study. Psychology, Health \& Medicine. 2016; 21(2):176-88. [DOI:10.1080/13548 506.2015.1051557] [PMID]

18. Gaudlitz K, Plag J, Dimeo F, Struhle A. Aerobic exercise training facilitates the effectiveness of cognitive behavioral therapy in panic disorder. Depression and Anxiety. 2015; 32(3):221-8. [DOI:10.1002/da.22337] [PMID]

19. Rodriguez Vazquez S, O'Brien S. A self-efficacy approach to assess the effectiveness of web Localisation and accessibility training. 1st International Conference on Translation and Cultural Sustainability: Foundations, Fundamentals and Applications, Salamanca, Spain; 2018.

20. Drossman DA. Functional gastrointestinal disorders: history, pathophysiology, clinical features, and Rome IV. Gastroenterology. 2016; 150(6):1262-79. [DOI:10.1053/j. gastro.2016.02.032] [PMID]

21. Sacco R, Santangelo G, Stamenova S, Bisecco A, Bonavita S, Lavorgna $\mathrm{L}$, et al. Psychometric properties and validity of Beck Depression Inventory II in multiple sclerosis. European Journal of Neurology. 2016; 23(4):744-50. [DOI:10.1111/ene.12932] [PMID]

22. Mohammadkhani P, Dobson KS, Massah Choolaby O, Asari $\mathrm{S}$. Determine the rule of gender in relation between sexual desire and quality of life in patients with major depression. Journal of Rehabilitation. 2011; 12(1):27-33.

23. Alizadeh Aghdam MB, Koohi K, Gholizadeh M. The relationship of self-care and health literacy with mental health among citizens of Tabriz city. Journal of Health Based Research. 2017; 2(4):381-94.

24. Bagheri Z, Jafari P, Mahmoodi M, Dabbaghmanesh MH. Testing whether patients with diabetes and healthy people perceive the meaning of the items in the Persian version of the SF-36 questionnaire similarly: a differential item functioning analysis. Quality of Life Research. 2017; 26(4):835-45. [DOI:10.1007/s11136-016-1419-y] [PMID]
25. Stajkovic AD, Bandura A, Locke EA, Lee D, Sergent K. Test of three conceptual models of influence of the big five personality traits and self-efficacy on academic performance: A metaanalytic path-analysis. Personality and Individual Differences. 2018; 120:238-45. [DOI:10.1016/j.paid.2017.08.014]

26. Peyman N, Zadehahmad Z, Doosti $H$. The effect of education based on self-efficacy theory on self-care behaviors in patients with heart failure in Shahid Modarres Hospital in Kashmar. Journal of Health in the Field. 2018; 5(4):1-7.

27. Hejazi S, Peyman N, Tajfard M, Esmaily H. The impact of education based on self-efficacy theory on health literacy, self-efficacy and self-care behaviors in patients with type 2 diabetes. Iranian Journal of Health Education and Health Promotion. 2017; 5(4):296-303. [DOI:10.30699/acadpub. ijhehp.5.4.296]

28. Corona LL, Christodulu KV, Rinaldi ML. Investigation of school professionals' self-efficacy for working with students with ASD: Impact of prior experience, knowledge, and training. Journal of Positive Behavior Interventions. 2017; 19(2):90-101. [DOI:10.1177/1098300716667604]

29. Havyer RD, van Ryn M, Wilson PM, Griffin JM. The effect of routine training on the self-efficacy of informal caregivers of colorectal cancer patients. Supportive Care in Cancer. 2017; 25(4):1149. [DOI:10.1007/s00520-018-4607-1] [PMID]

30. Ramezani T, Sharifirad G, Gharlipour Z, Mohebi S. Effect of educational intervention based on self-efficacy theory on adherence to dietary and fluids-intake restriction in hemodialysis patients. Health Education and Health Promotion. 2018; 6(1):31-8. [DOI:10.29252/HEHP.6.1.31]

31. Torres del Rey J, Rodriguez Vazquez S, S6nchez Ramos MD. Showcasing web accessibility and localisation training: the example of culture and heritage websites. Acceso al patrimonio cultural, cientrfico y natural. Contribuciones Desde La Traductologна. 2019; 3(2):19-42. 